\title{
On the Role of Typhoons in Generating PJ Teleconnection Patterns over the Western North Pacific in Late Summer
}

\author{
Ryuichi Kawamura and Takuya Ogasawara \\ Department of Earth Sciences, University of Toyama, Toyama, Japan
}

\begin{abstract}
The extratropical response to typhoon-related convective forcing over the western North Pacific in late summer is examined based on ECMWF global reanalysis (ERA-40) data during the 1958-2001 period. Typhoon activity is intimately associated with most of the major events in which an extratropical wavetrain structure prevails from the north of the Philippines through the central North Pacific. The vertical structure of the wavetrain pattern changes from baroclinic to a barotropic along the great circle. The analysis of the wave activity flux indicates that the extratropical wavetrain is stimulated by stationary Rossby waves. It was found that one or two typhoons, which are a synoptic-scale convective heat source over the western North Pacific, can induce the barotropic Rossby wavetrain and significantly influence the summer weather in the vicinity of Japan as remote forcing.
\end{abstract}

\section{Introduction}

The existence of a summertime extratropical wave train associated with anomalous tropical convection around the Philippine Sea has been demonstrated by Nitta (1987) and Huang and Li (1987). Nitta (1987) defined such a wave train as the Pacific-Japan (PJ) teleconnection pattern. It is well known that this teleconnection pattern affects the anomalous summer climate in East Asia, especially Japan, through changes in the North Pacific or Bonin highs (e.g., Kurihara and Tsuyuki 1987; Nitta and Hu 1996; Kawamura et al. 1998; 2001; Ueda and Kawamura 2004; Wakabayashi and Kawamura 2004).

To explore the potential predictability of the anomalous summer climate in East Asia, it would be meaningful to understand what kinds of convective heating generate the PJ teleconnection pattern. Previous studies have shown that the tropical Madden-Julian oscillation (MJO), which is of convective origin, systematically propagates northward or northwestward in the western North Pacific summer monsoon region (e.g., Wang and Rui 1990; Kawamura et al. 1996; Tsou et al. 2005). Kawamura et al. (1996) postulated that while the MJO is migrating northward, MJO-related convective forcing excites a barotropic Rossby wave train extending to the central North Pacific approximately along the great circle. Fukutomi and Yasunari (1999) also showed an extratropical wave train with a 10-25 day scale emanating out of the South China Sea.

Over the warm pool region of the western North Pacific, synoptic-scale disturbances, such as tropical cyclones, also supply convective heating in the troposphere as well as MJO. However, few studies have examined whether such synoptic-scale disturbances actually stimulate an extratropical teleconnection pattern. The main objectives of this study are (1) to examine how the PJ teleconnection pattern dominates

Corresponding author: Ryuichi Kawamura, University of Toyama, 3190 Gofuku, Toyama 930-8555, Japan. E-mail: kawamura@sci.toyama-u.ac.jp. @2006, the Meteorological Society of Japan. over the western North Pacific on a daily basis using a teleconnection index that is a diagnostic measure of the PJ activity, and (2) to discuss whether the tropical cyclones (typhoons) contribute significantly to the formation of the PJ teleconnection pattern.

\section{Data used and analysis procedures}

The datasets used in this study include: (1) reanalysis (ERA-40) data from the European Centre for Medium-Range Weather Forecasts (ECMWF) with a spatial resolution of $2.5^{\circ}$ longitude by $2.5^{\circ}$ latitude for the period 1958-2001, and (2) the typhoon track data compiled by the Japan Meteorological Agency (JMA) for the 1958-2001 period. The JMA defines a typhoon as a tropical cyclone with a maximum wind speed exceeding $17.2 \mathrm{~m} \mathrm{~s}^{-1}$ in the vicinity of its center.

Wakabayashi and Kawamura (2004) defined teleconnection indices that account for the variability of four teleconnection patterns associated with anomalous summer climate in Japan and its surrounding regions. $\mathrm{PJ}$ is one of the four teleconnection modes, and its index is given as:

$$
P J=\left[Z^{*}{ }_{850}\left(155^{\circ} \mathrm{E}, 35^{\circ} \mathrm{N}\right)-Z^{*}{ }_{850}\left(125^{\circ} \mathrm{E}, 22.5^{\circ} \mathrm{N}\right)\right] / 2,
$$

where $Z_{850}^{*}$ indicates the geopotential height anomalies at the $850-\mathrm{hPa}$ level. In this study, we used the daily mean geopotential height in late summer (August) derived from the ERA-40 to compute the PJ index for the 1958-2001 period. By applying a simple combination of two low-pass filters (3-day weighted running average and 31-day running average) to the daily data, we first excluded both the day-to-day fluctuations and the low-frequency components with periods of greater than about one month and, as a consequence, extracted the variability with time scales from half a week to two or three weeks. Second, we computed the standard deviation $(\sigma)$ of the band-pass-filtered PJ index and defined a period exceeding $+1.5 \sigma$ as an event in which the PJ pattern predominates from the north of the Philippines through the central North Pacific, but if the maximum peak of the index is obscure, we excluded such a case because we cannot specify the peak day of the PJ. Consequently, we extracted 18 events during the analyzed period and then constructed composite maps from day -2 to day +3 for the geopotential height, rainfall, and stream function anomalies. Here the "day 0 " denotes the peak day of the positive PJ index. These variables are filtered values in the same way as the PJ index.

\section{Results}

Figure 1 shows composites of 850 -hPa geopotential height anomalies during six days from day -2 to day +3 . The tracks of typhoons that are analyzed during the six days are also exhibited. From day -2 to day 0 , the PJ teleconnection pattern is established from the north of the Philippines through the central North Pacific south of Alaska. At day 0, a positive height anomaly east of Japan becomes most evident with a value of about +30 

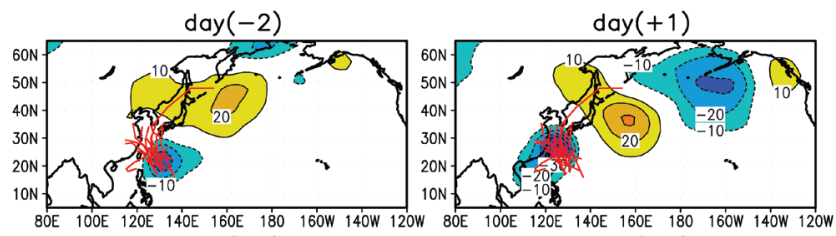

$\operatorname{day}(-1)$
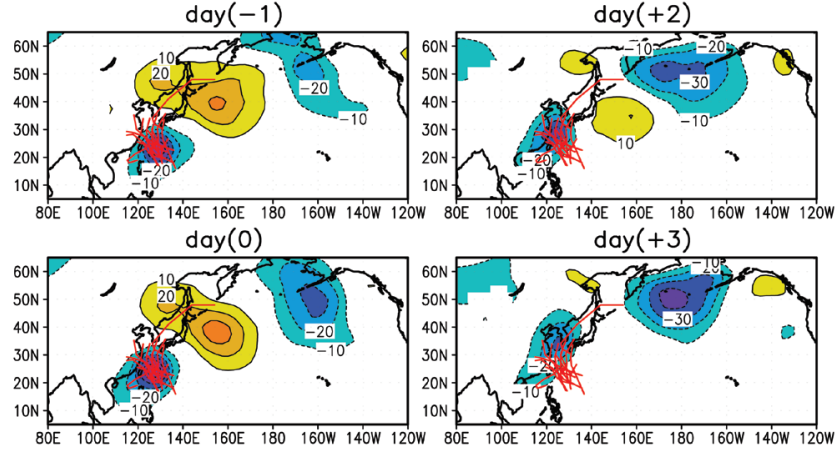

Fig. 1. Composite maps of filtered $850-\mathrm{hPa}$ geopotential height anomalies from day -2 to day +3 . Day 0 denotes the peak phase of the PJ. Eighteen events are used for the composite analysis when the PJ index is extremely large in August. The contour interval is $10 \mathrm{~m}$. Tropical cyclone tracks are also exhibited. The plot of the tracks is made using the total period from day -2 to day +3 .

m. From day 0 to day +2 , the positive anomaly gradually weakens and disappears at day +3 , whereas a negative anomaly in the vicinity of the Aleutian Islands strengthens and reaches it peak with a value of $-40 \mathrm{~m}$. The dominance of the negative anomaly is expected to correspond to the development of synoptic-scale extratropical cyclones near the Aleutian Islands. These features seem to be a manifestation of the northeastward energy propagation of quasi-stationary waves, which will be discussed later. Along the typhoon tracks, a negative height anomaly northeast of the Philippines migrates north-northwestward and reaches the East China Sea at day +3 , but at that time its magnitude is weak. As stated earlier, these composite maps are constructed based on 18 events when the PJ index exhibited a large positive value. The number of typhoons that were located in the vicinity of the Philippine Sea in these events is 15, implying that the appearance frequency of a typhoon is about $83 \%$. Thus, a typhoon can be interpreted as an element forming a negative height anomaly around the Philippine Sea in many cases.

Figure 2 shows the composite map of rainfall and 850-hPa geopotential height anomalies at day 0. A positive rainfall anomaly area exceeding $+5 \mathrm{~mm} \mathrm{day}^{-1}$ coincides well with the negative height anomaly just east of Taiwan. This suggests that anomalous convective heating due to enhanced rainfall is the origin of the PJ pattern. Figures 1 and 2 indicate that the anomalous rainfall around Taiwan is mainly driven by typhoon activities. Likewise, a negative rainfall anomaly is observed to the east of Japan in conjunction with a positive height anomaly, suggesting that the anomalous anticyclone suppresses convection there. A weak positive rainfall anomaly is also seen on the southern coast of Japan.

To validate whether the typhoon-related PJ pattern is a stationary Rossby wave teleconnection, the wave activity flux, defined by Takaya and Nakamura (2001), is calculated for the anomalous stream function field at the $850-\mathrm{hPa}$ level because the wavetrain pattern of the PJ is evident along a low-level westerly duct that is established by a combination of mid-latitude westerlies and monsoon westerlies (Kawamura et al. 1996). Figure

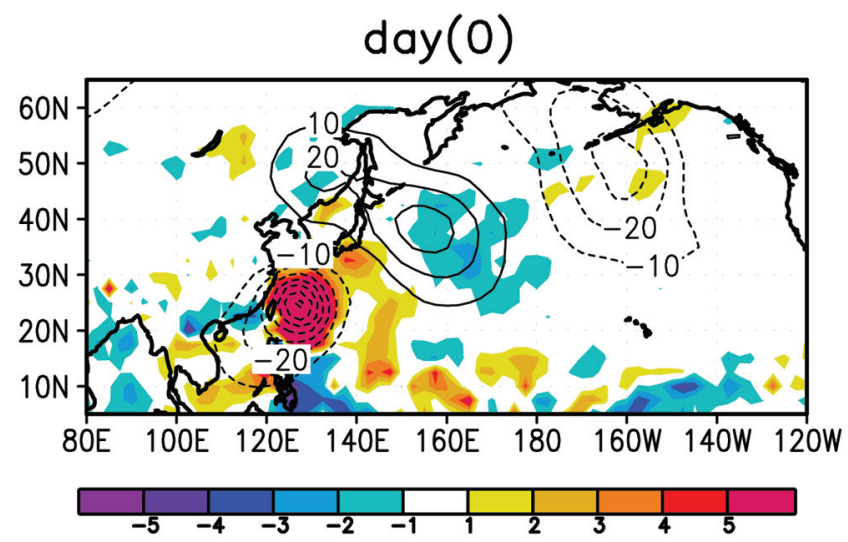

Fig. 2. Composite map of filtered rainfall and 850-hPa geopotential height anomalies at day 0 . The color shading interval for rainfall is $1 \mathrm{~mm} \mathrm{day}^{-1}$. The contour interval for height is $10 \mathrm{~m}$.

3 reveals the composite maps of the $850-\mathrm{hPa}$ stream function anomalies and wave activity flux from day -2 to day +3 along with $200-\mathrm{hPa}$ stream function anomalies. At day -2 , anomalous anticyclonic circulation to the east of Japan has an approximately barotropic structure, but its vertical structure gradually changes and the center of upper-level anomalous anticyclonic circulation is shifted to 5 degrees north of that of the lowlevel anticyclone anomaly at day 0 , indicating that a baroclinic component is also present. A typical equivalent barotropic structure can be seen in the anomalous cyclonic circulation growing around the Aleutian Islands from day 0 to day +3 . An upper-level cyclonic circulation anomaly is located between a low-level anomalous anticyclone east of Japan and an anomalous cyclone north of the Philippines from day -2 to day 0 . To the south of Japan, baroclinic structures are dominant in the anomaly field. Thus, the vertical structure of the PJ is characterized by the transition from a baroclinic structure in the vicinity of anomalous convective forcing to an equivalent barotropic structure along the mid-latitude westerlies over the North Pacific. Such a vertical structure is very similar to that of the MJO-related PJ pattern examined by Kawamura et al. (1996). According to their study, the anomalous cyclonic circulation around the Aleutian Islands, initially originated by the PJ, can further develop due to the barotropic interaction between the mid-latitude westerlies and intraseasonal disturbances.

A notable feature in the wave activity flux field is the pronounced northward flux from the north of the Philippines to the vicinity of Japan from day -2 to day 0 , demonstrating the northward propagation of stationary waves. At day 0, the wave activity flux around the anomalous anticyclone east of Japan is northeastward, and distinctive eastward fluxes are observed along the wave-train over the North Pacific. Thus, the PJ teleconnection pattern can be identified with a stationary Rossby wavetrain induced by the anomalous convective heating over the Philippine Sea. From day +1 on, the northward fluxes to the south of Japan gradually weaken, whereas the eastward fluxes near the Aleutian Islands, accompanied with the anomalous cyclonic circulation, still persist until day +3 .

As already indicated in Fig. 1, the typhoon activity contributes significantly to the occurrence of the PJ pattern in late summer. To confirm that one or two typhoons can indeed induce the PJ pattern, we show a typical case in Fig. 4. This figure shows the $850-\mathrm{hPa}$ geopotential height anomalies during the period from August 9 to 12,1985 . The location of a typhoon at 09 

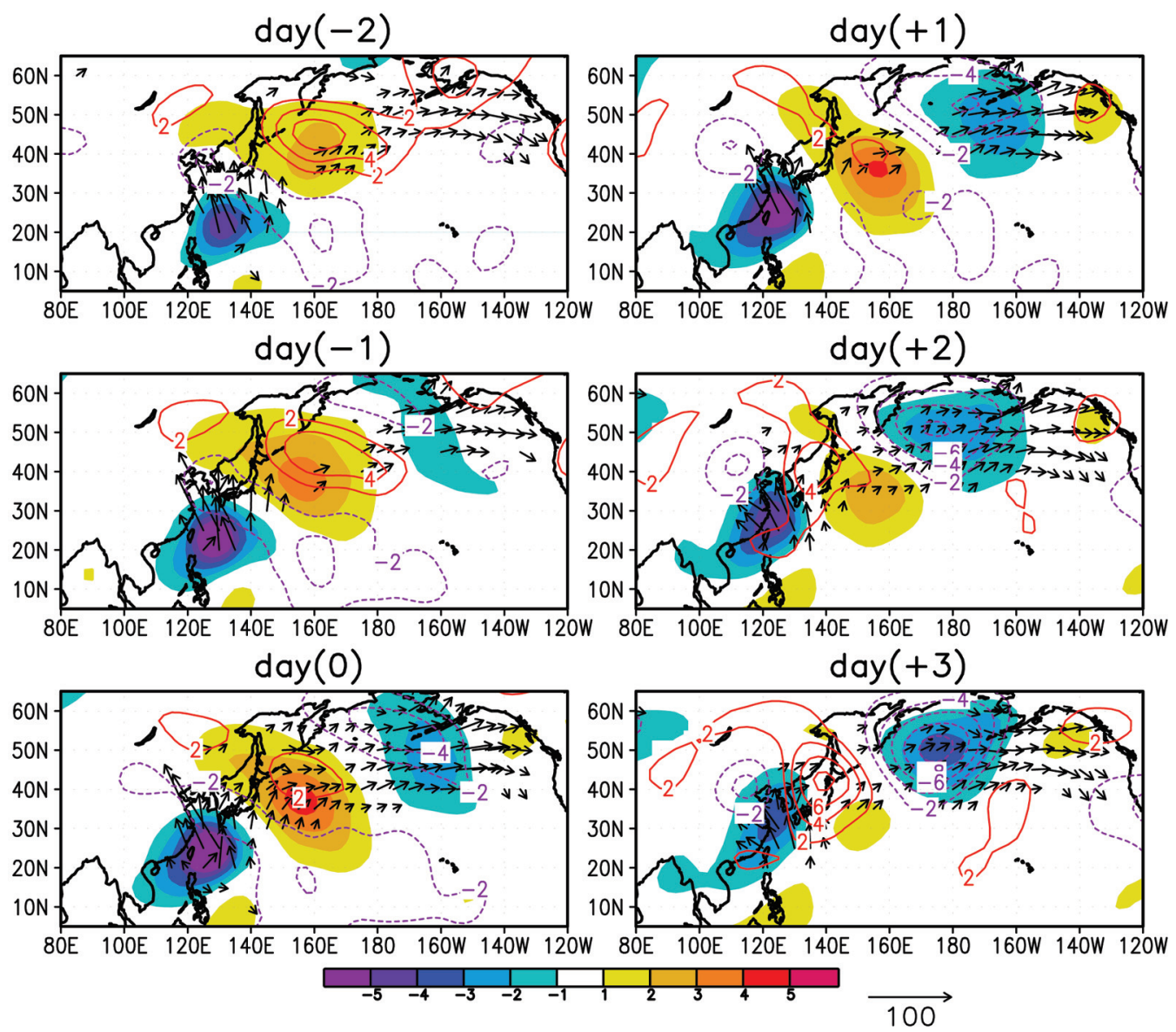

Fig. 3. Composite maps of filtered $850-\mathrm{hPa}$ stream function anomalies and wave activity flux from day -2 to day +3 . Day 0 denotes the peak phase of the PJ. The color shading interval for the 850 -hPa stream function is $1 \times 10^{6} \mathrm{~m}^{2} \mathrm{~s}^{-1}$. 200 -hPa stream function anomalies are also exhibited. The color contour interval for the 200-hPa stream function is $2 \times 10^{6} \mathrm{~m}^{2} \mathrm{~s}^{-1}$. The reference arrow is $100 \mathrm{~m}^{2} \mathrm{~s}^{-2}$. Fluxes of less than $10 \mathrm{~m}^{2} \mathrm{~s}^{-2}$ are suppressed.

LST is also plotted. August 10 is the peak phase of the PJ index. On August 9, a typhoon was observed over the East China Sea moving northeastward over the Japan Sea from August 10 to 12. Another typhoon that was moving slowly northward was established to the south of Japan on August 10. This example is the only one with two typhoons. The intensities of the two typhoons are comparable to other events.

In the meantime, the geopotential height anomaly filed in the lower troposphere demonstrates a wellorganized wave-train pattern across the North Pacific. On August 9, the center of the anomalous anticyclone to the east of Japan reached $+70 \mathrm{~m}$, but its magnitude decayed down to $+40 \mathrm{~m}$ on August 12 . In contrast, an anomalous cyclone over the central North Pacific developed up to $-90 \mathrm{~m}$. Another anticyclonic anomaly to the south of Alaska was also rapidly enhanced from August 9 to 12 , and its magnitude reaches $+130 \mathrm{~m}$ on August 12. Such an amplitude modulation implies that there is an eastward energy propagation of stationary waves. These features suggest that one or two typhoons could excite the PJ pattern as convective forcing, although it is not clear which typhoon contributes more largely to the excitement of the PJ. The establishment of the PJ tends to intensify the east-west pressure gradient at low levels between a typhoon and an anomalous anticyclone east of Japan, resulting in the reinforcement of southerly geostrophic winds across central Japan. The dominance of the southerly winds brings about enhanced warm advection and moisture supply from the lower latitudes. Such synoptic conditions often trigger heavy rain along the Pacific Ocean side of mainland Japan, even though a typhoon is far away from the mainland. At the same time, a salient foehn often occurs along the coast of the Japan Sea. Once large-scale circulation anomalies related to PJ are initiated and sustained as a result of the extratropical response, on the other hand, the development and movement of adjacent synopticscale disturbances such as typhoons are significantly regulated by the PJ-related anomalies (Inaba et al. 2002). Actually, the typhoons tend to migrate northnorthwestward to the south of Japan under the westward extention of the North Pacific High (see Fig. $1)$.

\section{Summary}

In this study, we examined on a daily basis how typhoon activity is related to the occurrence of the stationary wave propagation over the western North Pacific in late summer and made composite anomaly maps for the geopotential height, rainfall, stream function, and wave activity flux on the basis of a diagnostic teleconnection index. We extracted 18 events when the PJ index exhibited a large positive value and found that the typhoon activity is closely associated with 15 of the 18 events. The transition from a baroclinic structure in the vicinity of anomalous convective heating to an equivalent barotropic 


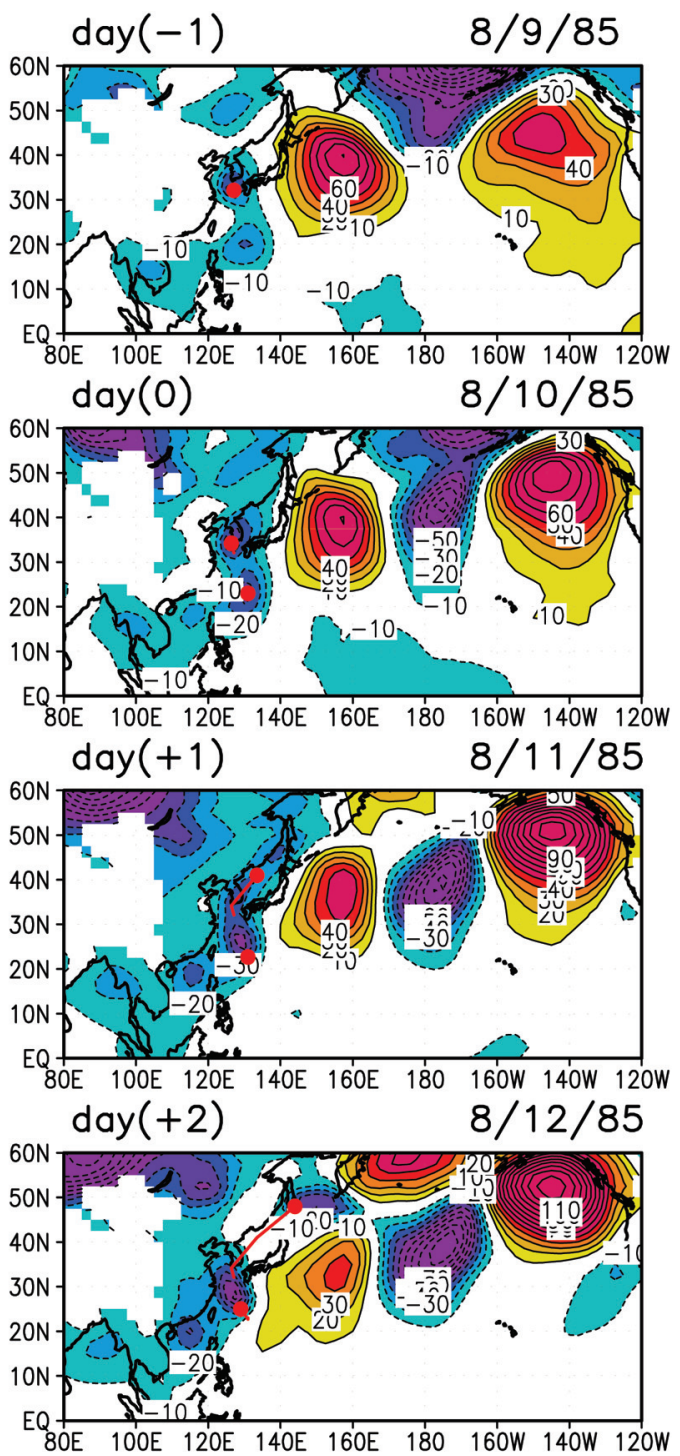

Fig. 4. Spatial patterns of filtered $850-\mathrm{hPa}$ geopotential height anomalies during the period from 9 August (day -1 ) to 12 August (day +2$)$ 1985. The contour interval is $10 \mathrm{~m}$. The location of typhoons at $09 \mathrm{LST}$ is also plotted by red circles.

structure along the mid-latitude westerlies over the North Pacific characterizes the vertical structure of the PJ. The analysis of the wave activity flux also supports the idea that the PJ teleconnection pattern is identified with a stationary Rossby wavetrain induced by the anomalous convective heating over the Philippine Sea. It is also suggested that one or two typhoons can trigger the PJ pattern as convective forcing. The establishment of the PJ intensifies an east-west pressure gradient at low levels between a typhoon and an anomalous anticyclone east of Japan, eventually facilitating enhanced warm advection and a moisture supply from lower latitudes. Such synoptic conditions often bring about heavy rain along the coast of the Pacific Ocean of the mainland of Japan and/or a pronounced foehn along the coast of the Japan Sea.

Although we examined a plausible dynamical link between the typhoon activity and the PJ pattern prevailing only in August, it would be worthwhile to explore the seasonal relationship between the two from early summer to late autumn. The PJ pattern hardly appears during autumn, probably because the low-level westerly duct that is a necessary condition for a PJ is not formed without summer monsoon westerlies (Kawamura et al. 1996); however, the typhoon activity becomes more active in autumn and the typhoons develop in higher latitudes as is well known. It is uncertain how these contradictory conditions modulate the link between the typhoon activity and the PJ pattern, which will be reported later.

\section{Acknowledgments}

This research was supported by the research project "R\&D of hydrological modeling and water resources system" of JST/CREST, and by the research project "Refinement of global and regional water cycle" of the Japanese Ministry of Education, Sports, Culture, Science and Technology.

\section{References}

Fukutomi, Y., and T. Yasunari, 1999: 10-25 day intraseasonal variations of convection and circulation over East Asia and the western North Pacific during early summer. J. Meteor. Soc. Japan, 77, 753-769.

Huang, R. H., and W. J. Li, 1987: Influence of the heat source anomaly over the western tropical Pacific on the subtropical high over East Asia. Proc. International conference on the general circulation of East Asia, 40-51.

Inaba, H., R. Kawamura, T. Kayahara, and H. Ueda, 2002: Extraordinary persistence of foehn observed in the Hokuriku district of Japan in the 1999 summer. J. Meteor. Soc. Japan, 80, 579-594.

Kawamura, R., T. Murakami, and B. Wang, 1996: Tropical and midlatitude 45-day perturbations over the western Pacific during the northern summer. J. Meteor. Soc. Japan, $\mathbf{7 4}$ 867-890.

Kawamura, R., M. Sugi, T. Kayahara, and N. Sato, 1998: Recent extraordinary cool and hot summers in East Asia simulated by an ensemble climate experiment. J. Meteor. Soc. Japan, 76, 597-617.

Kawamura, R., T. Matsuura, and S. Iizuka, 2001: Interannual atmosphere-ocean variations in the tropical western North Pacific relevant to the Asian summer monsoon-ENSO coupling. J. Meteor. Soc. Japan, 79, 883-898.

Kurihara, K., and T. Tsuyuki, 1987: Development of the barotropic high around Japan and its association with Rossby wave-like propagations over the North Pacific: analysis of August 1984. J. Meteor. Soc. Japan, 65, 237-246.

Nitta, T., 1987: Convective activities in the tropical western Pacific and their impact on the Northern Hemisphere summer circulation. J. Meteor. Soc. Japan, 65, 373-390.

Nitta, T., and Z.-Z. Hu, 1996: Summer climate variability in China and its association with $500 \mathrm{hPa}$ height and tropical convection. J. Meteor. Soc. Japan, 74, 425-445.

Takaya, K., and H. Nakamura, 2001: A formulation of a phaseindependent wave-activity flux for stationary and migratory quasigeostrophic eddies on a zonally varying basic flow. J. Atmos. Sci., 58, 608-627.

Tsou, C.-H., P.-C. Hsu, W.-S. Kau, and H.-H. Hsu, 2005: Northward and northwestward propagation of 30-60 day oscillation in the tropical and extratropical western North Pacific. J. Meteor. Soc. Japan, 83, 711-726.

Ueda, H., and R. Kawamura, 2004: Summertime anomalous warming over the midlatitude Western North Pacific and its relationship to the modulation of the Asian monsoon. Int. J. Climatology, 24, 1109-1120.

Wakabayashi, S., and R. Kawamura, 2004: Extraction of major teleconnection patterns possibly associated with anomalous summer climate in Japan. J. Meteor. Soc. Japan, 82, $1577-1588$.

Wang, B., and H. Rui, 1990: Synoptical climatology of transient tropical intraseasonal convection anomalies: 1975-1985. Meteor. Atmos. Phys., 44, 43-62.

Manuscript received 21 December 2005, accepted 9 February 2006 SOLA: http://www.jstage.jst.go.jp/browse/sola/ 